high maternal and neonatal mortality. The Institute of Healthcare Improvement (IHI) is supporting the Ethiopian Federal Ministry of Health in implementing a comprehensive QI initiative focusing on quality planning, building QI/management capability, and designing and testing a scalable district-wide approach for health improvement embedded into the routine system.

Objectives The aims of this initiative are to 1) introduce a feasible and scalable district-wide improvement approach; 2) improve quality of health services and outcomes in Ethiopia, as measured by selected maternal and newborn health (MNH) priority indicators including three labor and delivery clinical bundles.

Methods A total of 3,307 and 26,186 medical records were reviewed over the 17 -month baseline period and 12-month intervention period respectively. Bundle compliance was plotted using P-charts. Service coverages were calculated using estimated eligible population and U-charts were used to assess improvement.

Results After the intervention, 84\% (110/131) of participating facilities report greater than $90 \%$ adherence to at least one labor and delivery bundle, and 67\% (88/131) of facilities report greater than $90 \%$ adherence to all labor and delivery bundles. The median clinical bundle adherence in the post intervention period is above $80 \%$ for all three bundles. $70 \%$ (92/131) of facilities report improvement as determined by run chart rules in at least one service coverage outcome (ANC4, SBA, or PNC within 48 hours).

Conclusions Findings from this study can be used to strengthen obstetric health service quality throughout Ethiopia and other similar contexts.

\section{IMPROVING THE WORKPLACE EXPERIENCE FOR PEDIATRICIANS IN AN ACADEMIC PRACTICE}

Heather McLean, Jennifer Lawson, Tracy Spears, Angelo Milazzo, Susan Kline, Kathleen McGann, Coleen Cunningham, Ann Reed. Duke University Medical Center, USA

\subsection{6/bmjoq-2019-ihi.17}

Background Physician burnout has a negative effect on the quality of care; however, effective interventions are lacking.

Objectives To identify and impact key drivers of physician workplace satisfaction in an academic pediatric department.

Methods A quality improvement approach was used to impact key drivers of faculty workplace satisfaction. In 2017, 2018, and 2019 faculty completed anonymous surveys that combined the Maslach Burnout Inventory(MBI) and Areas of Worklife Survey(AWS). Interventions included changes to compensation plan, clinical practice, departmental communication, workplace community, individual wellness, and culture. Descriptive statistics and data visualization were performed. Two-sided t-tests and ANOVA regression analysis were used to compare responses.

Results Survey completion rates were: 160/195 (82\%) in $2019 ; 139 / 180(77 \%)$ in 2018 ; and $155 / 171$ (91\%) in 2017; 101 physicians completed all three surveys. Statistically significant improvements were observed in reward (3.4 vs $3.3 ; \mathrm{p}<0.05)$ and values $(3.6$ vs $3.5 ; \mathrm{p}<0.05)$ domains of the AWS in 2019 and 2018 versus 2017. MBI average scores were similar in all three years, and remained significantly better than the general population in depersonalization $(1.0$ vs. $1.7 ; \mathrm{p}<0.0001)$ and personal accomplishment
Key driver diagram

Pediatric Faculty Workplace Project Key Driver Diagram (KDD)

Project Leader(s): Heather McLean, Jennifer Lawson

Revision Date: 08/09/2019 (v4)

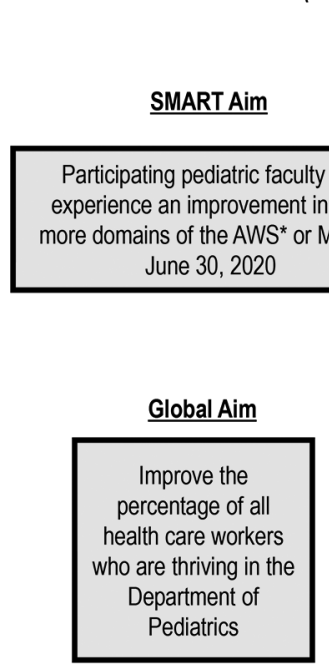

*AWS=Areas of Worklife Survey; MBI=Maslach Burnout Inventory

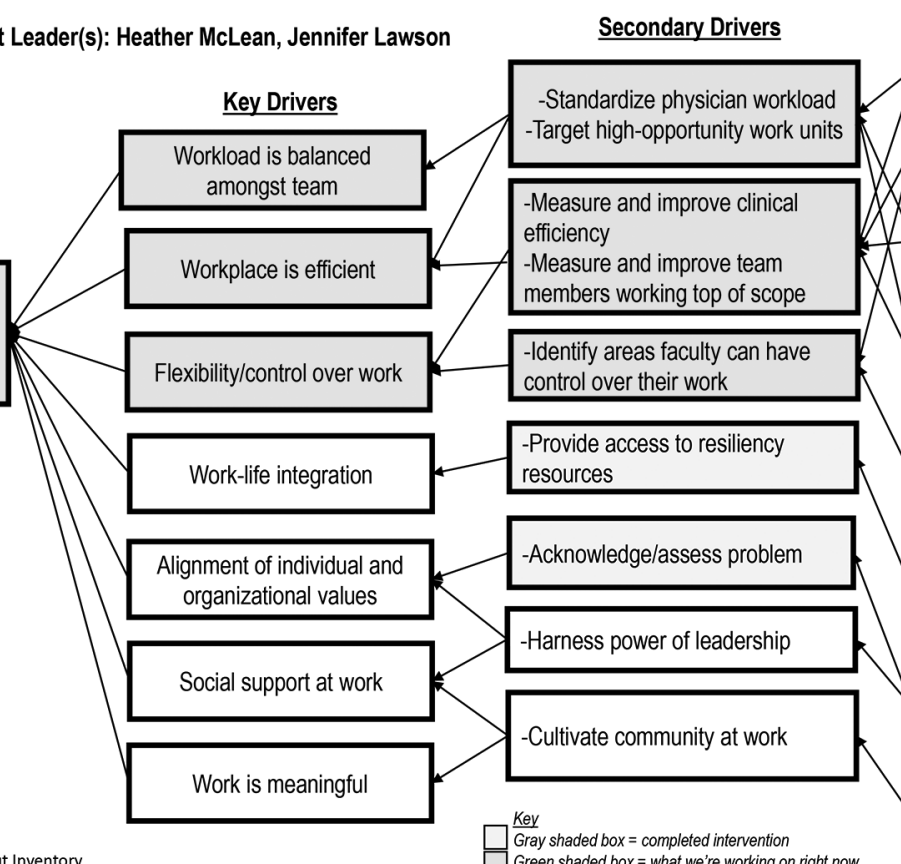

Green shaded box $=$ what we're working on right now 

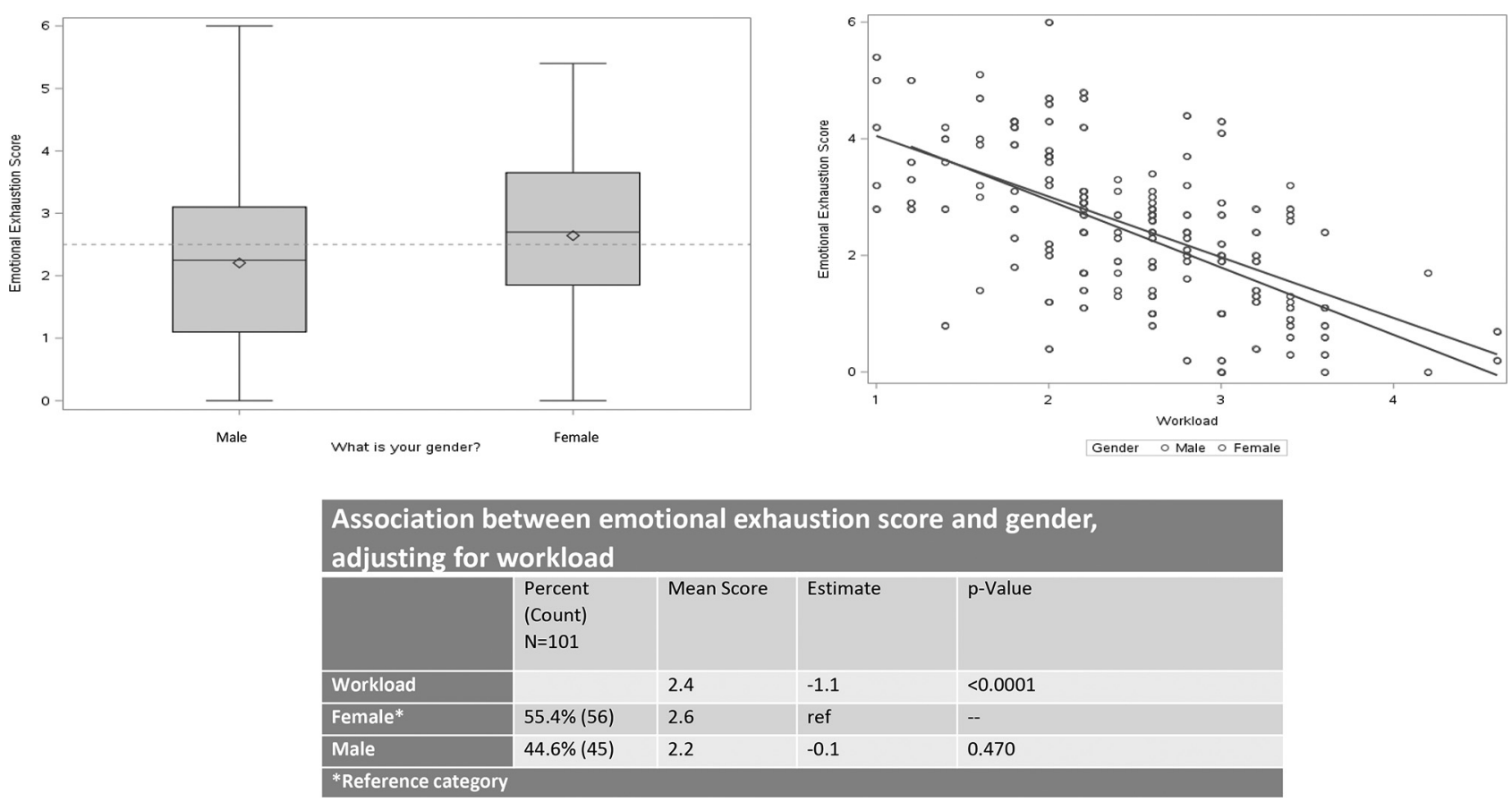

Abstract 17 Figure 2 Association between emotional exhaustion score and gender, adjustiong for workload for 101 participants responding in 2017, 2018 and 2019 using ANOVA regression analysis. A lower mean score in emotional exhaustion domain is better
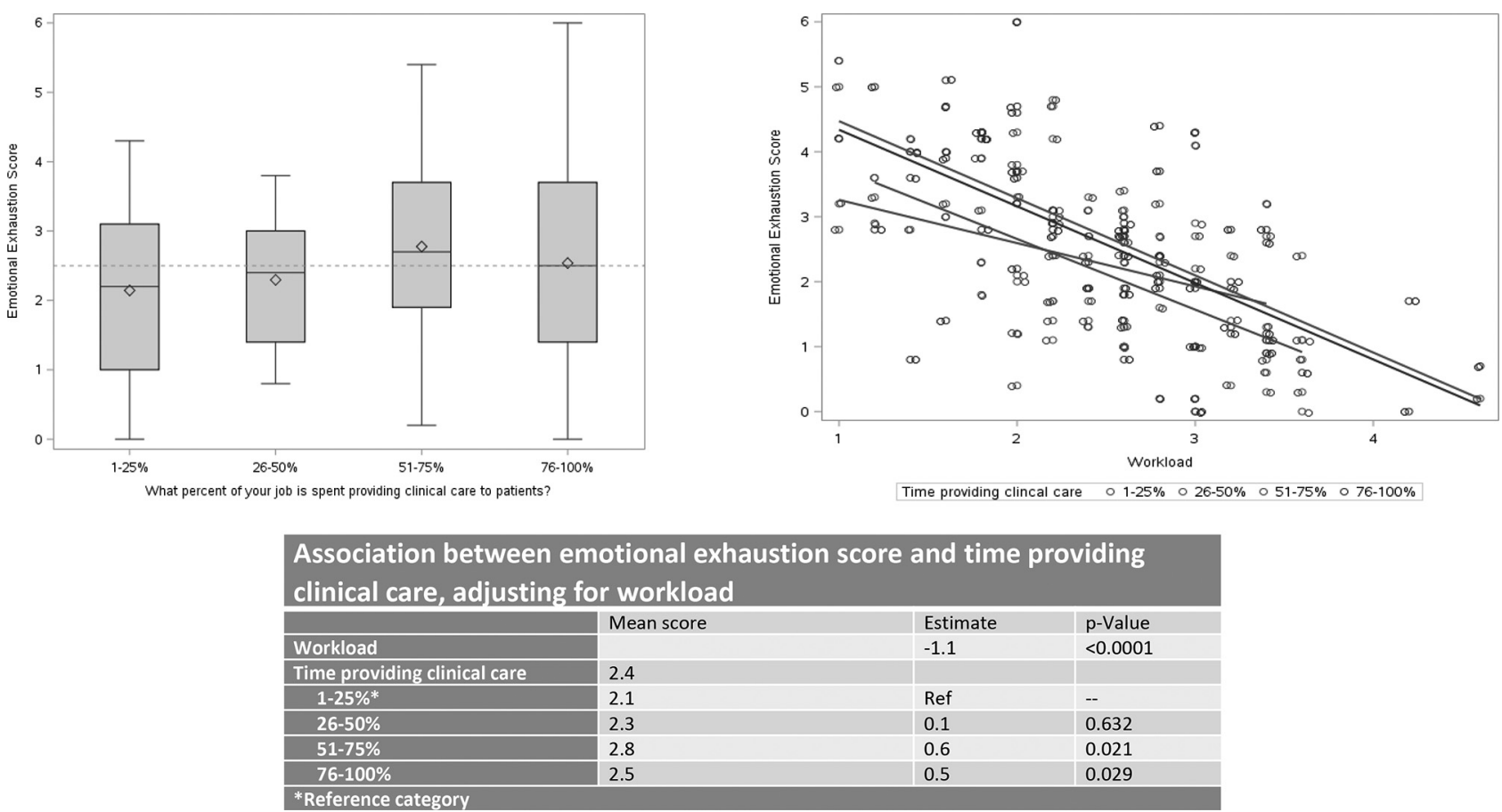

Abstract 17 Figure 3 Association between emotional exhaustion score and percent of tme providing clinical care, adjustiong for workload for 101 participants responding in 2017, 2018 and 2019 using ANOVA regression analysis. A lower mean score in emotional exhaustion domain is better

domains $(5.0$ vs. $4.3 ; \mathrm{p}<0.0001)$. There was no difference in the emotional exhaustion domain. Worse emotional exhaustion scores were reported in women $(2.8$ vs 2.1 ; $\mathrm{p}<0.05)$ and those working $>75 \%$ clinical effort $(2.8$ vs $2.1 ; \mathrm{p}<0.05)$.
Conclusions Interventions targeting the workplace improved physicians' experience of reward and values. Risk factors associated with a high emotional exhaustion score included female gender or individuals working $>75 \%$ clinical effort. 
Abstract 17 Table 1 Average ratings of the Maslach Burnout Inventory (MBI) and Areas of Worklife Survey (AWS) compared to norms of participants ( $\mathrm{N}=101)$ responding to the survey all three years. The 'general population' for AWS survey includes people across a diversity of organizations whereas it includes health care workers for the MBI. Participant scores for depersonalization, personal accomplishment, reward, community, fairness, and values are better than the general population. The response for reward and fairness became significantly better in 2018 and 2019 compared to 2017. The average participant score for workload is worse than the general population

\begin{tabular}{|c|c|c|c|}
\hline Section & $\begin{array}{c}\text { Results } \\
\text { Mean (sd) }\end{array}$ & $\begin{array}{c}\text { General Population } \\
\text { Mean (sd) }\end{array}$ & $p$-Value \\
\hline \multicolumn{4}{|l|}{ Maslach Burnout Inventory } \\
\hline Emotional Exhaustion & $2.5(1.3)$ & $2.3(1.2)$ & 0.1101 \\
\hline Depersonalization & $1.0(0.9)$ & $1.7(1.2)$ & $<0.0001$ \\
\hline Personal Accomplishment & $5.0(0.7)$ & $4.3(0.9)$ & $<0.0001$ \\
\hline \multicolumn{4}{|l|}{ Areas of Worklife Survey } \\
\hline Workload & $2.4(0.7)$ & $3.0(0.8)$ & $<0.0001$ \\
\hline Control & $3.2(0.9)$ & $3.3(0.9)$ & 0.4949 \\
\hline Reward & $3.4(0.9)$ & $3.2(0.9)$ & 0.0305 \\
\hline Community & $4.0(0.7)$ & $3.4(0.8)$ & $<0.0001$ \\
\hline Fairness & $3.2(0.7)$ & $2.8(0.8)$ & $<0.0001$ \\
\hline Values & $3.6(0.6)$ & $3.2(0.8)$ & $<0.0001$ \\
\hline
\end{tabular}

$s d=s t a n d a r d$ deviation

Abstract 17 Table 2 Average ratings of the Areas of Worklife Survey (AWS) compared to norms in 2017, 2018, and 2019. The 'general population' for AWS survey includes people across a diversity of organizations. Participant scores for depersonalization, personal accomplishment, reward, community, fairness, and values are better than the general population. The response for reward and fairness became significantly better in 2018 and 2019 compared to 2017. The average participant score for workload is worse than the general population

\begin{tabular}{|c|c|c|c|c|c|c|c|}
\hline Section & $\begin{array}{l}\text { General Population } \\
\text { Mean (sd) } \\
\mathrm{N}=22,500\end{array}$ & $\begin{array}{c}\text { Pediatric } \\
\text { Faculty } 2017 \\
\text { Mean (sd) } \\
\text { N=155 }\end{array}$ & $\begin{array}{c}2017 \text { p-Value vs } \\
\text { General } \\
\text { Population }\end{array}$ & $\begin{array}{l}\text { Pediatric Faculty } \\
2018 \text { Mean (sd) } \\
\text { N=139 }\end{array}$ & $\begin{array}{c}2018 \text { p-Value vs } \\
\text { General } \\
\text { Population }\end{array}$ & $\begin{array}{l}\text { Pediatric Faculty } \\
2019 \text { Mean (sd) } \\
\text { N=160 }\end{array}$ & $\begin{array}{c}2019 \text { p-Value vs } \\
\text { General } \\
\text { Population }\end{array}$ \\
\hline \multicolumn{8}{|c|}{ Areas of Worklife Survey } \\
\hline Workload & $3.0(0.8)$ & $2.2(0.7)$ & $<0.0001$ & $2.4(0.8)$ & $<0.0001$ & $2.5(0.7)$ & $<0.0001$ \\
\hline Control & $3.3(0.9)$ & $3.2(0.9)$ & 0.2955 & $3.3(0.9)$ & 0.5710 & $3.3(0.9)$ & 0.4996 \\
\hline Reward & $3.2(0.9)$ & $3.3(0.8)$ & 0.0818 & $3.5(0.8)$ & $<0.0001$ & $3.4(0.9)$ & 0.0004 \\
\hline Community & $3.4(0.8)$ & $3.9(0.8)$ & $<0.0001$ & $3.9(0.7)$ & $<0.0001$ & $3.9(0.7)$ & $<0.0001$ \\
\hline Fairness & $2.8(0.8)$ & $3.0(0.8)$ & 0.0012 & $3.2(0.7)$ & $<0.0001$ & $3.2(0.7)$ & $<0.0001$ \\
\hline Values & $3.2(0.8)$ & $3.5(0.7)$ & $<0.0001$ & $3.6(0.5)$ & $<0.0001$ & $3.6(0.6)$ & $<0.0001$ \\
\hline
\end{tabular}

p-Values based on two-sided one sample t-Tests

$\mathrm{sd}=$ standard deviation

\section{RESOLVING PEDIATRIC POPULATION-LEVEL GAPS:} SUCCESS OF AN INREACH MODEL

'John Morehous, ${ }^{2}$ Cynthia White, ${ }^{1}$ Dominick DeBlasio, ${ }^{2}$ Allison Glance, 3 Julie Kleiman, ${ }^{4}$ Srikant Iyer. ${ }^{1}$ Cincinnati Children's Hospital Medical Center, University of Cincinnati College of Medicine, USA; ${ }^{2}$ James M. Anderson Center for Health Systems Excellence, Cincinnati Children's Hospital Medical Center, USA; ${ }^{3}$ Cincinnati Children's Hospital Medical Center, USA; ${ }^{4}$ Children's Healthcare of Atlanta, Emory University School of Medicine, USA

\subsection{6/bmjoq-2019-ihi.18}

Background Primary care settings have implemented processes to resolve population-level care gaps, including patient reminders, health record prompts, and outreach to patients/ families. When patients present outside of primary care but still within the larger health system, these primary-care based processes are not applied, and opportunities to resolve care gaps are missed. We hypothesized that we could resolve care gaps outside the primary care setting by creating an 'inreach' process within the larger healthcare system.

Objectives Among children 2-66 months of age within our primary care registry, we aimed to identify and resolve care gaps for children admitted to the hospital medicine service, Our goal was to contact the inpatient team for at least $80 \%$ of these patients, and to increase the percent of care gaps closed from $30 \%$ to $50 \%$.

Methods A multidisciplinary team of physicians, nurses and improvement experts mapped the baseline process. Failure modes were predicted, and a key driver diagram was 